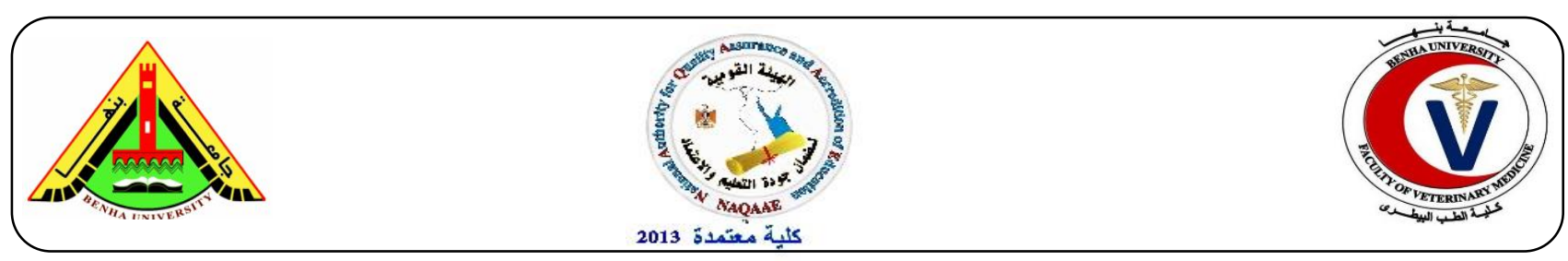

\title{
Ameliorating role of resveratrol on biochemical changes in experimentally- induced liver fibrosis in rats
}

\author{
Samy Ali Hussein ${ }^{*}$; Samir Abdel Latif Abdel Aal ${ }^{2}$; Mohammed Bader Abd El-Aziem ${ }^{3}$ and \\ Hisham Fathey EL Said ${ }^{1}$ \\ ${ }^{1}$ Biochemistry Department, Faculty of Vet. Med., Benha University, Egypt. \\ ${ }^{2}$ Department of Animal, Poultry and Environmental Hygiene, Faculty of Vet. Med., Benha \\ University, Egypt. \\ ${ }^{3}$ Animal Health Research Institute, Zagazig branch. \\ ${ }^{1 *}$ Corresponding author: Samy Ali Hussein; email: samyaziza@yahoo.com samy.aziza@ fvtm.bu.edu.eg
}

\begin{abstract}
Liver fibrosis is the final pathway stage of most chronic liver diseases, and is the main reason for increased mortality in affected patients. Hence, this study was undertaken to evaluate the hepatoprotective effect and the efficacies of resveratrol against thioacetamide (TAA) induced liver fibrosis in rats. The experimental model of liver fibrosis in rats was induced by intraperitoneal (i.p) injection of TAA at a dose $(200 \mathrm{mg} / \mathrm{Kg}$ b.wt / thrice / week) for 6 weeks. A total of fifty five male rats were used in this study. All rats were divided into four groups. Group I: (Control normal group) rats received no drugs. Group II: (TAA- group). Group III: (TAA + resveratrol protected group) rats injected with TAA and administered resveratrol $(0.5 \mathrm{mg} / \mathrm{Kg}$ body weight / day, intraperitoneally) from the $7^{\text {th }}$ week to $12^{\text {th }}$ week. Group IV: (TAA + resveratrol treated group) rats firstly injected with TAA from the $1^{\text {st }}$ week to $6^{\text {th }}$ week and treated daily with resveratrol $(0.5$ $\mathrm{mg} / \mathrm{Kg}$ body weight, intraperitoneally) from the $7^{\text {th }}$ week to $12^{\text {th }}$ week. Blood samples and liver tissue were taken and processed directly for some biochemical parameters determination. The obtained results revealed that, a significant increase in serum ALT, AST and ALP activities, IL-6, TGF- $\beta 1$ and liver L-MDA concentrations were observed in TAA injected rats. However, administration of resveratrol to TAA induced liver fibrosis in rats exhibited a significant decreased in all mentioned parameters and attenuated the increased L-MDA concentration in liver tissues. On the other hand, a significant decrease in liver antioxidant enzymes (SOD and CAT) activities were observed in TAA injected rats when compared with control normal group. Meanwhile, resveratrol administration resulted in a significant increase in liver SOD and CAT activities. It could be concluded that, inhibition of lipid peroxidation, inflammation and oxidative stress and enhanced antioxidant enzymatic status in rats liver by resveratrol suggest the potential efficiency of resveratrol as a natural hepatoprotective and anti-inflammatory agent in treatment of liver fibrosis.
\end{abstract}

Key words: Thioacetamide (TAA), resveratrol (RSV), oxidative stress, inflammatory markers, liver fibrosis. 


\section{INTRODUCTION}

Liver is a vital organ that plays a major role in metabolism, energy production and bile production, storage of iron, vitamins and trace elements, detoxification and conversion of waste products for excretion by the kidneys (Phyllis, 2012). Fibrosis is an important cause of liver dysfunction and portal hypertension (Roskams et al., 2003). There is increasing evidence that, unlike cirrhosis, fibrosis is treatable and reversible in its early stages (Fowell and Iredale, 2006). Knowledge of the stage of fibrosis is crucial for patient care because patients with mild disease should be monitored and those with advanced disease must be treated (Marcellin et al., 2002). Liver injury or liver dysfunction is a major health problem that challenges not only health care professionals but also the pharmaceutical industry and drug regulatory agencies. Liver cell injury caused by various toxicants (certain antibiotic, chemotherapeutic agents, carbon tetrachloride $\left(\mathrm{CCL}_{4}\right)$, thioacetamide (TAA), D-galactosamine, paracetamol, excessive alcohol consumption and microbes are well-studied (Vuyyuri et al., 2014). TAA is a widely used sulfur-containing compound both in the laboratory and in various technical applications and can also be present in the environment as organic sulfur compounds (Zaleska et al., 2007). Thioacetamide is a highly specific hepatotoxic material causing liver injury and dysfunction, containing thiono-sulfur compound and is well known to induce hepatic damage by generation of reactive oxygen species (ROS) (Wang et al., 2012). Shortly, after its administration, the thiono-sulfur group of TAA undergoes an extensive metabolism by the mixed function oxidase system in the body to produce acetamide, that does not have liver necrotizing properties, and TAA-S-oxide by a microsomal monooxygenases requiring NADPH and cytochrome P450 (Baskaran et al., 2010). In a further step, TAA-S-oxide is transformed to TAA-S-S-dioxide, which is a highly reactive unstable compound that is thought to covalently binding to liver macromolecules and responsible for initiation of hepatic damage and centrilobular necrosis, (Chilakapati et al., 2005), and generation of ROS that leads to hepatocellular death via oxidative stress (Sarkar and Sil, 2007).

In recent years, there has been renewed interest in the treatment against different diseases using herbal drugs as they are generally non-toxic and World Health Organization has also recommended the evaluation of the effectiveness of plants in condition where we lack safe modern drugs (Ayyanar et al., 2008).

In particular, resveratrol $\left(3,44^{\prime}, 5-\right.$ trihydroxystilbene) a natural polyphenol, is synthesized by various plants in response to injurious substances (Engelhard et al., 2004). It is a compound belonging to the stilbene class of aromatic phytochemicals existing in cis and trans forms. RSV is predominantly found in nature in peanuts (Arachis hypogaea) (Sanders et al., 2000) and grapes (Vitis vinifera) (Burns et al., 2002).Other natural sources of resveratrol include mulberries, blueberries, cranberries, bilberries, turmeric, and hops (Lyons et al., (2003); Baur and Sinclair, (2006)). It has broad physiological and pharmacological functions including antioxidation, antiplatelet agglomeration, modulation of blood lipid metabolism, antiinflammation and inhibition of tumor growth (Hong et al., (2009); Hassan-Khabbar et al., (2010)). Accordingly, the present study aimed to evaluate the hepatoprotective and treatment effects of RSV as a natural antioxidant agent 
on liver fibrosis induced by thioacetamide (TAA) in rats.

\section{MATERIAL AND METHODS}

\subsection{Experimental animals:}

Fifty-five white male albino rats of 8-10 weeks old and weighting 150- $200 \mathrm{~g}$ were used in the experimental investigation of this study. Rats were obtained from the Laboratory Animals Research Center, Faculty of Veterinary Medicine, Benha University, housed in separated metal cages and kept at constant environmental and nutritional conditions throughout the period of experiment. The animals were fed on constant ration and water was supplied ad-libitum. The rats were left 15 days for acclimatization prior to the beginning of the experiment.

\subsection{Chemicals and antioxidants:}

2.2.1 Thioacetamide (TAA): TAA Known as thioacetamide acid, or acetothioamide the molecular formula $\left(\mathrm{CH}_{3} \mathrm{CSNH}_{2}\right)$. TAA exists at room temperature as colorless to yellow crystals with a slight odor of mercaptans. It is highly soluble in distilled water and physiological saline. Thioacetamide was purchased from Sigma Aldrich Company Co. for Trading Chemicals, Medicines and Medical Appliances.

Induction of liver fibrosis: Thioacetamide was freshly dissolved in $0.9 \% \mathrm{NaCL}$ solution, and administered to rats at a dose level of (200 $\mathrm{mg} / \mathrm{kg} \mathrm{b.wt/i.p.)} 3$ times per week for 6 weeks for induction of liver fibrosis (Said et al., 2013).

2.2.2 Resveratrol (RSV): Resveratrol (3,5,4'trihydroxystilbene) is a stilbenoid, a derivate of stilbene, with the molecular formula $\mathrm{C}_{14} \mathrm{H}_{12} \mathrm{O}_{3}$, molecular weight 228.2 , melting point $261-263{ }^{\circ} \mathrm{C}$, white powder with yellow casts and highly soluble in normal saline or 5\% ethanol. Resveratrol (purity 98\%) was obtained as bottle contains $500 \mathrm{mg}$ resveratrol in the crystalline form. Resveratrol manufactured by Sigma Chemical Co. (St. Louis, Mo, USA) and purchased from Schnelldorf, Germany through the Egyptian International Center for Import Cairo, Egypt.

Preparation and dosage of Resveratrol: Resveratrol was freshly prepared in 5\% Ethanol, and administered to rats at a dose level of $(0.5 \mathrm{mg} / \mathrm{kg}$ b.wt/day, i.p.) for 6 weeks (Su et al., 2006).

\subsection{Experimental design:}

After acclimatization, rats were randomly divided into four groups, each group contains 10 rats except group II contains 25 rats placed in individual cages and classified as follow:

Group I: (Control normal group) rats received no drugs served as control for all experimental groups.

Group II: (TAA-group): This group was divided into 2 subgroups:

Subgroup (a) (TAA-induced liver fibrosis for protected group) rats injected TAA (200mg/Kg b.wt / thrice / week, i.p) for 6 weeks from $7^{\text {th }}$ week to $12^{\text {th }}$ week.

Subgroup (b) (TAA-induced liver fibrosis for treated group) rats injected TAA $(200 \mathrm{mg} / \mathrm{Kg}$ b.wt / thrice / week, i.p) for 6 weeks from $1^{\text {st }}$ week to $6^{\text {th }}$ week.

Group III: (TAA+ resveratrol protected group) rats injected TAA $(200 \mathrm{mg} / \mathrm{Kg}$ b.wt / thrice / week, i.p) for 6 weeks from $7^{\text {th }}$ week to $12^{\text {th }}$ week, at the same time resveratrol injected intraperitoneally from $7^{\text {th }}$ week to $12^{\text {th }}$ week at dose level $(0.5 \mathrm{mg} / \mathrm{Kg}$ b. wt./ day).

Group IV: (TAA+ resveratrol treated group) rats injected TAA $(200 \mathrm{mg} / \mathrm{Kg}$ b.wt / thrice / week, i.p) for 6 weeks from $1^{\text {st }}$ week to $6^{\text {th }}$ 
week, then resveratrol administrated intraperitoneally daily from $7^{\text {th }}$ week to $12^{\text {th }}$ week at dose level $(0.5 \mathrm{mg} / \mathrm{Kg} \mathrm{b}$. wt.).

\subsection{Sampling:}

Blood samples and tissue specimen (liver) were collected from all animal groups (control and experimental groups) at the end of experiment.

\subsubsection{Blood samples:}

At the end of the experimental period (12 weeks) rats were fasted overnight, then blood samples were collected from the retro-orbital venous plexus located at the medial canthus of the eye by means of heparinized capillary tubes.

Blood samples were collected in dry, clean test tubes and incubated for $1 / 2 \mathrm{hr}$ at room temperature to allow clotting for serum separation. Clear sera were separated by centrifugation at 3500 r.p.m. for 15 minutes and then collected in Eppendorf's tubes using automatic micropipettes and kept in a deep freeze at $-20^{\circ} \mathrm{C}$ until used for subsequent biochemical analysis. All serum samples were analyzed for determination of the following parameters: ALT, AST, ALP, interleukin-6 (IL-6) and transforming growth factor- $\beta 1$ (TGF- $\beta 1$ ).

\subsubsection{Liver tissue for biochemical analysis:}

After finishing blood sampling, rats of each group were sacrificed by decapitation and the liver was rapidly excised clean by rinsing with ice-cold isotonic saline, and then blotted between 2 filter papers. These tissue samples were quickly frozen in a deep freezer at ($20^{\circ} \mathrm{C}$ ) for subsequent biochemical analyses. All liver samples were analyzed for determination of superoxide dismutase (SOD), catalase (CAT) and Lmalondialdehyde (L-MDA).

\subsection{Biochemical analysis:}

Serum ALT, AST, ALP activities, IL-6 and TGF- $\beta 1$ concentrations were determined according to the methods described by (Pappas, (1989); Tietz, (1995); My BioSource Rat IL-6 ELISA Kit, Catalog Number: (MBS 175908); Rat TGF- $\beta 1$ ELISA Kit, Catalog Number: (SEA124Ra), respectively. Moreover, liver tissue L-malondialdehyde (LMDA) concentration, catalase (CAT) and superoxide dismutase (SOD) activities were determined according to the methods described by (Mesbah et al., (2004); Fossati et al., (1980); Nishikimi et al., (1972)), respectively.

\subsection{Statistical analysis:}

The results were expressed as mean \pm standard error (SE) to evaluate variations in data. The obtained data were analyzed and graphically represented using the statistical package for social science (SPSS, 14.0 software, 2008), for obtaining mean and standard deviation and error. The data were analyzed using one-way ANOVA to determine the statistical significance of differences among groups. Duncan's test was used for making a multiple comparisons among the groups for testing the intergrouping homogeneity. Significance was accepted at $p \leq 0.05$.

\section{RESULTS}

The obtained data presented in tables ( 1 and 2) revealed that, a significant increase in serum ALT, AST, ALP activities, IL-6 and TGF- $\beta 1$ concentrations were observed in TAA induced liver fibrosis in rats when compared with control normal group. Whereas, in resveratrol protected and treated groups a significant decreases in serum ALT, AST, ALP activities, IL-6 and TGF- $\beta 1$ 
concentrations were observed when compared with TAA treated group.

Moreover, liver L-MDA concentration was significantly increased and SOD and CAT activities were significantly decreased in TAA induced liver fibrosis in rats when compared with control normal group. Whereas, in resveratrol protected and treated groups a significant decrease in serum ALT, AST, ALP activities, IL-6 and TGF- $\beta 1$ concentrations were observed when compared with TAA treated group. However, in resveratrol protected and treated groups a significant decrease in L-MDA concentration and marked increases in SOD and CAT activities were observed in liver tissues when compared with TAA treated group.

Table (1): Protective effect of resveratrol on some serum and liver tissue parameters in thioacetamide-induced liver fibrosis in rats.

Animals Group

Serum parameters:

$\operatorname{ALT}(\mathrm{U} / \mathrm{L})$

$\operatorname{AST}(\mathrm{U} / \mathrm{L})$

$\operatorname{ALP}(\mathrm{U} / \mathrm{L})$

IL-6 $(\mathrm{Pg} / \mathrm{ml})$

TGF- $\beta 1(\mathrm{Pg} / \mathrm{ml})$

Liver parameters:

SOD (U/g. tissue)

CAT (U/g. tissue)

L-MDA (nmol/g.tissue)
Control Normal Group

$82.04 \pm 4.32^{\mathrm{d}}$

$130.42 \pm 3.07^{\mathrm{c}}$

$195.98 \pm 3.52^{\mathrm{d}}$

$77.00 \pm 2.92^{\mathrm{c}}$

$9.73 \pm 0.36^{\mathrm{d}}$

$513.00 \pm 16.84^{\mathrm{a}}$

$43.00 \pm 1.65^{\mathrm{a}}$

$38.40 \pm 1.29^{\mathrm{d}}$
TAA Group

$193.43 \pm 6.99^{\mathrm{a}}$

$295.27 \pm 7.15^{\mathrm{a}}$

$386.74 \pm 6.51^{\mathrm{a}}$

$128.59 \pm 6.77^{\mathrm{a}}$

$44.59 \pm 0.56^{\mathrm{a}}$

$278.99 \pm 9.48^{\mathrm{c}}$

$21.20 \pm 0.75^{\mathrm{c}}$

$89.70 \pm 2.37^{\mathrm{a}}$
TAA + Resveratrol Protected

$100.34 \pm 5.37^{\mathrm{c}}$

$157.39 \pm 2.31^{\mathrm{b}}$

$240.37 \pm 4.46^{\mathrm{c}}$

$94.71 \pm 3.59^{\mathrm{b}}$

$36.63 \pm 0.38^{c}$

$407.80 \pm 12.02^{\mathrm{b}}$

$33.07 \pm 1.29^{\mathrm{b}}$

$46.99 \pm 1.43^{\mathrm{c}}$

Data are presented as (Mean \pm S.E). S.E $=$ standard error. Mean values with different superscript letters in the same row are significantly different at $(P<0.05)$.

Table (2): Treatment effect of resveratrol on some serum and liver tissue parameters in thioacetamide-induced liver fibrosis in rats.

\section{Animals Group}

Serum parameters:
$\operatorname{ALT}(\mathrm{U} / \mathrm{L})$
$\operatorname{AST}(\mathrm{U} / \mathrm{L})$
$\operatorname{ALP}(\mathrm{U} / \mathrm{L})$
IL-6 (Pg/ml)

TGF- $\beta 1(\mathrm{Pg} / \mathrm{ml})$

Liver parameters:

SOD (U/g. tissue)

CAT (U/g. tissue)

L-MDA (nmol/g.tissue)
Control Normal Group

$$
\begin{gathered}
82.04 \pm 4.32^{\mathrm{c}} \\
130.42 \pm 3.07^{\mathrm{d}} \\
195.98 \pm 3.52^{\mathrm{d}} \\
77.00 \pm 2.92 \mathrm{c} \\
9.73 \pm 0.36^{\mathrm{c}}
\end{gathered}
$$

$513.00 \pm 16.84^{\mathrm{a}}$

$43.00 \pm 1.65^{\mathrm{a}}$

$38.40 \pm 1.29^{\mathrm{d}}$
TAA Group

$205.73 \pm 7.38^{\mathrm{a}}$

$313.68 \pm 7.17^{\mathrm{a}}$

$411.91 \pm 6.89^{\mathrm{a}}$

$135.80 \pm 7.54^{\mathrm{a}}$

$59.34 \pm 2.41^{\mathrm{a}}$

$256.80 \pm 7.99^{\mathrm{c}}$

$21.00 \pm 0.71^{\mathrm{c}}$

$95.40 \pm 2.51^{\mathrm{a}}$
TAA + Resveratrol Treated

$$
\begin{aligned}
& 133.59 \pm 4.78^{b} \\
& 204.48 \pm 5.06^{c} \\
& 261.96 \pm 3.82^{c} \\
& 88.92 \pm 4.68^{\mathrm{cb}} \\
& 45.56 \pm 0.27^{b} \\
& 342.12 \pm 9.67^{b} \\
& 27.00 \pm 0.96^{b} \\
& 61.89 \pm 1.69^{\mathrm{c}}
\end{aligned}
$$


Data are presented as (Mean \pm S.E). S.E $=$ standard error. Mean values with different superscript letters in the same row are significantly different at $(P<0.05)$.

\section{DISCUSSION}

Liver fibrosis is a consequence of sustained chronic injury from a variety of causes, including viral, drug-induced, autoimmune, cholestatic, and metabolic diseases (Friedman, 2003). The obtained data demonstrated in tables (1 and 2) revealed that, a significant increase in serum ALT, AST, ALP activities, IL-6 and TGF- $\beta 1$ concentrations were observed in rats injected with TAA for 6 weeks when compared with control normal group. These results came in accordance with Zhang et al., (2017); Seif ElDin et al., (2016); Mahfouz et al. (2016); Akdemir et al. (2016); Algandaby (2016) who reported that, rats injected with TAA caused a significant increase in serum AST and ALT activities as compared to control normal group. Also, Haghighi et al., (2013); Wang et al., (2011c); Shaker et al., (2011a) reported that, the injection of rats with TAA produced a significant increase of ALP activity when compared with control normal group.

In addition, the marked elevation of serum IL6 concentration in TAA injected rats came in accordance with (Bashandy et al., (2017); Mona et al, (2017); Seif El-Din et al., (2016)) who reported that, serum IL-6 concentration was significantly elevated in TAA-treated rats when compared with control normal group. Moreover, Akdemir et al., (2016); Baraka and Guemei, (2015); Mona et al., (2013) reported that, serum TGF- $\beta 1$ concentrations was significantly elevated in TAA ijected rats when compared with control group. Increased activities of AST, ALT may be interpreted as a result of the liver cell destruction or changes in the membrane permeability indicating severe hepatocellular damage induced by TAA, which is in accordance with other recorded by (Schmatz et al., 2012) and this showed the stress condition of the TAA treated animals. Jain and Singhai, (2011) interpreted the elevated levels of AST and ALT as a result of the hepatocytes damage or alterations in the membrane permeability indicating the severity of hepatocellular damage induced by TAA, which is in accordance with previous reports of (Sehrawat et al., 2006). In the current study, the rise in AST and ALT activities induced by TAA were significantly reduced after RSV administration when compared with TAAinduced liver fibrosis. The protective and treatment activity of RSV might be due its effect against cellular leakage and loss of functional integrity of the cell membrane in hepatocyte. Elevation of serum ALT, AST, ALP and bilirubin in blood often reflect hepatocellular damage. Resveratrol acts as a hepatoprotective agent is reported to have a protective effect on the plasma membrane of hepatocytes (Rivera et al., 2008). Diminishment in ALP after resveratrol treatment is also indicative of its membrane stabilizing activity (Fan et al., 2009).

On the other hand, administration of resveratrol whatever treatment or protective with TAA significantly decreased serum IL-6 concentration as compared with TAA injected rats group. This result was in agreement with (Birrell et al., (2005); Ma et al., (2005); Bujanda et al., (2008); Bisht et al., (2010)) who reported that, resveratrol exhibited antiinflammatory effect in vitro and in vivo and inhibited the release of inflammatory cytokines such as IL-6. Also, administration of resveratrol to TAA induced liver fibrosis in rats significantly decreased the concentration of serum TGF- $\beta 1$ as compared with TAA alone. Similarly, Hong et al., (2010) 
investigated the protective effect of resveratrol on dimethyl nitrosamine (DMN)induced liver fibrosis in rats and observed that, resveratrol showed a reduction in mRNA expression of fibrosis-related genes such as transforming growth factor beta 1 (TGF- $\beta 1$ ). Also, Lee et al., (2010) shown that, oral administration of resveratrol $(20 \mathrm{mg} / \mathrm{kg}$ daily for 4 weeks) remarkably prevented the DMNinduced loss in body and liver weight and the reduction in transforming growth factor- $\beta 1$ mRNA expression.

The current study revealed that, administration of TAA to normal rats exhibited a significant reduction in liver SOD and CAT activities when compared with control normal group. The present study showed the oxidative/anti-oxidative status in the liver after TAA administration causes a significant decrease in the antioxidant enzyme activities and increased lipid peroxidation as reported by Sarkar and Sil, (2007) who showed that, TAA treatment caused depletion in the activity of antioxidant enzymes (CAT and SOD); therefore, it could be said that, TAA caused the cellular damage by inhibiting the activity of the antioxidant enzymes.

Higher pro-oxidant liver status in rats with TAA is likely to involve a high consumption of cellular and circulated antioxidants. This could be partly related to the decrease in the liver activity of CAT. However, an important compensatory mechanisms like the upregulation of SOD activity, is developed by the liver. It could indicate an activation of cellular defense mechanisms in order to protect the hepatocytes from harmful consequences caused by oxidative stress (Lebovitz et al., (1996); Suttorp et al., (1986)). Catalase is responsible for breakdown of $\mathrm{H}_{2} \mathrm{O}_{2}$ an important ROS, formed during the reaction catalyzed by SOD, reduced activity of catalase after exposure to
TAA could be correlated to increased generation of $\mathrm{H}_{2} \mathrm{O}_{2}$ (Ansil et al., (2011).

In the present study, administration of RSV whatever treatment or protective with TAA significantly increased liver SOD and CAT activities when compared with TAA alone. This results are nearly similar to those reported by Hong et al., (2010) who investigated the protective effect of resveratrol on dimethyl nitrosamine (DMN)induced liver fibrosis in rats. Who showed that, resveratrol increased the activity of SOD. Also, Simão et al., (2011) reported that, treatment with RSV markedly reversed the alterations and almost restored to near normal activities in enzymatic parameters SOD and CAT brought about by ischemia/reperfusion. Treatment with resveratrol prevented the reduction in SOD and CAT activity in liver of streptozotocin-induced diabetic rats, indicating a possible role of this polyphenol in free radical inactivation and in the antioxidant defense (Schmatz et al., (2012)). Also, (Cao and Li, (2004); Leonard et al., (2003) reported that, resveratrol is able to up-regulate mRNA expression for antioxidant enzymes. Based on these findings, we can suggest that, resveratrol is able to modulate SOD and CAT activities, which may be very important since it increases the scavenging capacity of ROS of liver providing higher protection against oxidative damage in this tissue. This suggestion was confirmed by Leonard et al., (2003) who reported that, the reactivation in SOD activity promoted by resveratrol may accelerate the dismutation of $\mathrm{O}^{2-}$ to $\mathrm{H}_{2} \mathrm{O}_{2}$, which is quickly removed by CAT protecting the hepatic tissues against highly reactive and toxic hydroxyl radicals and consequently preventing the lipid peroxidation.

The obtained results revealed that, administration of TAA to normal rats exhibited a significant increase in liver LMDA concentration when compared with 
control normal group. These results came in agreement with Ansil, et al., (2011); Shaker et al., (2011b); Baraka and Guemei, (2015); Seif El-Din et al., (2016); Akdemir et al. (2016) who reported that, TAA administration resulted in a significant increase in hepatic MDA concentration as compared to control normal group. MDA is the main product of lipid peroxidation and its concentration usually reflects the total level of lipid peroxidation (Tsai et al., 2010). TAA has been found to stimulate lipid peroxidation by generation of ROS (Bruck, et al., 1999). Administration of RSV whatever protective or treatment to liver fibrosis induced in rats significantly decreased L-MDA concentration. This result came in agreement with Kumar et al., (2007) who reported that, a significant reduction in brain MDA concentration was observed in diabetic rats treated with RSV. Similarly, Sebai et al., (2010) recorded a significant reduction in liver MDA concentration to near control concentration was observed in rats pretreated with RSV against lipopolysaccharide induced lipoperoxidation. Also, Sehirli et al., (2008) recorded that, RSV caused a significant reduction in hepatic MDA concentration of naphthalene treated rats toward the control levels. Numerous investigations have reported that, resveratrol inhibited effectively the lipid peroxidation of cellular membranes, the protein oxidation as well as the DNA damage due its ability to directly scavenge various free radicals, including superoxide radicals and peroxyl and hydroxyl radicals (Leonard et al., (2003); Bradamante et al., (2004). Moreover, Eybl et al., (2006) reported that, rat pretreatment with RSV abolished the inductive effect of cadmium on hepatic lipid peroxidation. Resveratrol has been reported to prevent oxidative stress and lipid peroxidation (LPO) (Chávez et al., (2008), which might be due to the phenolic moiety present in its structure. The ability of the resveratrol is to exert protective effect against intoxication by reducing the MDA production that is indicative of its antioxidant activity.

\section{CONCLUSION}

In conclusion, the findings of the present study demonstrated that, resveratrol (RSV) administration provided an effective protection and treatment option against hepatic fibrosis and oxidative damage in liver induced by TAA in rats, since these natural antioxidant agent were able to ameliorate serum biomarkers of hepatic function, enzymatic antioxidant defense system, prevent the lipid peroxidation and oxidative stress in hepatic tissues. From my point of view as shown in the current study protective effect of RSV is more efficient than treatment.

\section{References}

Akdemir, B.; Bahcecioglu, I. H.; Tuzcu, M.; Orhan, C.; Ispiroglu, M.; Ozercan, I. H.; Ilhan, N.; Celik, N. C. and Sahin, K. (2016): Effect of lycopene and genistein on hepatic inflammation and fibrosis in thioacetamide induced liver injury in rats. British Journal of Medicine and Medical Research; 18(6): 1-11.

Algandaby, M. M. (2016): Antifibrotic effects of crocin on thioacetamide-induced liver fibrosis in mice. Saudi Journal of Biological Sciences, http://dx.doi.org/10.1016/j.sjbs.2016.1 0.007 .

Ansil, P. N.; Nitha, A.; Prabha, S. P.; Wills, P. J.; Jazaira, V. and Latha, M. S. (2011): Protective effect of Amorphophallus campanulatus 
(Roxb.) Blume.tuber against thioacetamide induced oxidative stress in rats. Asian Pac. J. Trop. Biomed, 4, (11), 870-877.

Ayyanar, M.; Sankarasivaraman, K. and Ignacimuthu, S. (2008): Traditional herbal medicines used for the treatment of diabetes among two major tribal groups in South Tamil Nadu, India. Ethnobot Leaflets 12: 276-80.

Baraka, A. M. and Guemei, A. (2015): Can Pharmacological Targeting of Advanced Glycation End Products Provide Protection Against Experimentally Induced Liver Fibrosis? Bioch Pharmacol (Los Angel), 4:2. DOI: 10.4172/21670501.1000167.

Bashandy, S. A. E.; Alaamer, A.; Moussa, S. A. and Omara, E. (2017): Role of zinc oxide nanoparticles in alleviating hepatic fibrosis and nephrotoxicity induced by thioacetamide in rats. Canadian Journal of Physiology and Pharmacology, doi: 10.1139/cjpp2017-0247.

Baskaran, N.; Periyasam, V. and Venkatraman, A. C. (2010): Investigation ofantioxidant, antiinflammatory and DNA-protective properties of eugenol in thioacetamide-induced liver injury in rats. Toxicology 268: 204-212.

Baur, J. A. and Sinclair, D. A. (2006): Therapeutic potential of resveratrol: the in vivo evidence. Nat Rev Drug Discov, 5: 493-506.

Birrell, M. A.; McCluskie, K.; Wong, S.; Donnelly, L. E.; Barnes, P. J. and Belvisil, M. G. (2005): Resveratrol, an extract of red wine, inhibits lipopolysaccharide induced airway neutrophilia and inflammatory mediators through an NF- kappa Bindependent mechanism. FASEB J., 19, 840-841.

Bisht, K.; Wagner, K. H. and Bulmer, A. C. (2010): Curcumin, resveratrol and flavonoids as anti-inflammatory, cytoand DNA-protective dietary compounds. Toxicology, 278(1):88100.

Bradamante, S.; Barenghi, L. and Villa, A. (2004): Cardiovascular protective effects of resveratrol. Cardiovasc Drug Rev, 22 (3): 169-188.

Bruck, R.; Aeed, H.; Shirin, H.; Matas, Z.; Zaidel, L.; Avni, Y. and Halpern, Z. (1999): The hydroxyl radical scavengers dimethylsulfoxide and dimethylthiourea protect rats against thioacetamide induced hepatic failure. J. Hepatol.; 31(1):27-38.

Bujanda, L.; Hijona, E.; Larzabal, M.; Beraza, M.; Aldazabal, P.; Garcia-Urkia, N.; Sarasqueta, C.; Cosme, A.; Irastorza, B.; Gonzalez, A. and Arenas, J. I. Jr. (2008): Resveratrol inhibits nonalcoholic fatty liver disease in rats. B M C Gastroenterol, 8: 40.

Burns, J.; Yokota, T.; Ashihara, H.; Lean, M. E. J. and Crozier, A. (2002): Plant foods and herbal sources of resveratrol. J Agric Food Chem, 50: 3337-3340.

Cao, Z. Y. Li, (2004): Potent induction of cellular antioxidants and phase 2 enzymes by resveratrol in cardiomyocytes: protection against oxidative and electrophilic injury. Eur. J. Pharmacol. 489 (1-2), 39-48.

Chávez, E.; Reyes-Gordillo, K.; Segovia, J.; Shibayama, M.; Tsutsumi, V.; Vergara, P.; Moreno, M. G. and Muriel, P. (2008): Resveratrol 
prevents fibrosis, NF- $\kappa \mathrm{B}$ activation and TGF- $\beta$ increases induced by chronic $\mathrm{CCl}_{4}$ treatment in rats. J. Appl. Toxicol. 28 (1): 35-43.

Chilakapati, J.; Shankar, K.; Korrapati, M. C.; Hill, R. A. and Mahendale, H. M. (2005): Saturation toxic kinetics of thioacetamide: role in initiation of liver injury. Drug Metab Dispos 33, 1877-1885.

Engelhard, K.; Werner, C.; Eberspacher, E.; Pape, M.; Stegemann, U.; Kellermann, K.; Hollweck, R.; Hutzler, P. and Kochs, E. (2004): Influence of propofol on neuronal damage and apoptotic fators after incomplete cerebral ischemia and reperfusion in rats - a long-term observation. Anesthesiology, 101(4): 912-917.

Eybl, V.; Kotyzova, D. and Koutensky, J. (2006): Comparative study of natural antioxidants (curcumin, resveratrol and melatonin) in cadmium-induced oxidative damage in mice.Toxicology $225,150-156$.

Fan, G.; Tang, J. J.; Bhadauria, M.; Nirala, S. K.; Dai, F.; Zhou, B. Li , Y. and Liu, Z. L. (2009): Resveratrol ameliorates carbon tetrachloride-induced acute liver injury in mice. Environmental Toxicology and Pharmacology 28(3), 350-356.

Fossati, P.; Prencipe, L. and Berti, G. (1980): Use of 3, 5-dichloro-2 hydroxybenzenesulfonic acid/4aminophenazone chromogenic system in direct enzymic assay of uric acid in serum and urineClin.Chem.26 (2):22731.

Fowell, A. J. and Iredale, J. P. (2006): Emerging therapies for liver fibrosis. Dig Dis; 24: 174-183.
Friedman, S. L. (2003): fibrosis-from bench to bedside.J Hepatol; 38: S38-S53.

Haghighi, N. R.; Naghsh, N. and Mehrabani, D. (2013): The Protective Effect of Curcuma longa in ThioacetamideInduced Hepatic Injury in Rat .Global Journal of Pharmacology, 7 (2): 203207.

Hassan-Khabbar, S.; Vamy, M.; Cottart, C. H.; Wendum, D.; Vibert F.; Savouret, J. F.; Thérond, P.; Clot, J. P.; Waligora, A. J. and Nivet-Antoine, V. (2010): Protective effect of postischemic treatment with transresveratrol on cytokine production and neutrophil recruitment by rat liver. Biochimie, 92(4): 405-410.

Hong, S. W.; Jung, K. H.; Zheng, H. M.; Lee, H. S.; Suh, J. K.; Park, I. S.; Lee, D. H. and Hong, S. S. (2010): The protective effect of resveratrol on dimethylnitrosamine-induced liver fibrosis in rats. Arch Pharm Res; 33 (4):601-609.

Hong, Y. B.; Kang, H. J.; Kim, H. J.; Rosen, E. M.; Dakshanamurthy, S.; Rondanin, R.; Baruchello, R.; Grisolia, G.; Daniele, S. and Bae, I. (2009): Inhibition of cell proliferation by a resveratrol analog in human pancreatic and breast cancer cells. Exp. Mol. Med., 41(3): 151-160.

Jain, N. K. and Singhai, A. K. (2011): Protective effects of Phyllanthus acidus (L.) skeels leaf extracts on acetaminophen and thioacetamide induced hepatic injuries in Wistar rats. Asian Pac. J. Trop. Med., 4:470-474.

Kumar, A.; Kaundal, R. K.; Iyer, S. and Sharma, S. S. (2007): Effects of resveratrol on nerve functions, oxidative stress and DNA 
fragmentation in experimental diabetic neuropathy. Life Sciences 80 (2007) 1236-1244.

Lebovitz, R. M.; Zhang, H.; Vogel, H.; J Cartwright, J. R.; Dionne, L.; Lu, N.; Huang, S. and Matzuk, M. M. (1996):

Neurodegeneration, myocardial injury, and perinatal death in mitochondrial superoxide dismutase-deficient mice, Proc. Natl. Acad. Sci. U.S.A. 93: 9782-9787.

Lee, E. S.; Shin, M. O.; Yoon, S. and Moon, J. O. (2010): Resveratrol inhibits dimethylnitrosamine-induced hepatic fibrosis in rats. Arch Pharm Res; 33 (6):925-932.

Leonard, S. S.; Xia, C.; Jiang, B. H.; Stinefelt, B.; Klandorf, H.; Harris, G. K. and Shi, X. (2003): Resveratrol scavenges reactive oxygen species and effects radical-induced cellular responses. Biochem Biophys Res Commun, 309, 1017-1026.

Lyons, M. M.; Yu, C.; Toma, R. B.; Cho, S. Y.; Reiboldt, W.; Lee, J. and vanBreemen, R. B. (2003): Resveratrol in raw and baked blueberries and bilberries. J Agric Food Chem, 51(20): 5867-5870.

Ma, Z. H.; Ma, Q. Y.; Wang, L. C.; Sha, H. C.; Wu, S. L. and Zhang, M. (2005): Effect of resveratrol on peritoneal macro- phages in rats with severe acute pancreatitis. Inflamm Res, 54, 522-527.

Mahfouz, M. K.; Omnia, M. Abd El-Hamid; Emam M. A.; Menna, A. B. (2016): Biochemical and histopathological effect of probiotics on experimentally induced liver fibrosis in rat. Benha Veterinary Medical Journal, 31(2): $248-253$.
Marcellin, P.; Asselah, T. and Boyer, N. (2002): Fibrosis and diseases progression in hepatitis $\mathrm{C}$. Hepatology; 36: S47-S56.

Mesbah, L.; Soraya, B.; Narimane, S. and Jean, P. F. (2004): protective effect of flavonides against the toxicity of vinblastine cyclophosphamide and paracetamol by inhibition of lipid peroxydation and increase of liver glutathione. Haematol.7 (1): 59-67.

Mona, G. Amer; Nehad, F. Mazen; and Ahmed M. Mohamed (2017): Caffeine intake decreases oxidative stress and inflammatory biomarkers in experimental liver diseases induced by thioacetamide: Biochemical and histological study. International Journal of Immunopathology and Pharmacology, 30(1) 13-24.

Mona, M. Ftahy; Noha, S. Abdl Latif; Essam, F. A.; Fatma, A. El-Batrawi; Ahmad, H. G. and Hany M. K. (2013): Antifibrotic potential of a selective $\mathrm{COX}_{-2}$ inhibitor (celecoxib) on liver fibrosis in rats. Comparative Clinical Pathology, 22 (3), 425-430.

Nishikimi, M.; Rao, N. and Yagi, K. (1972): "The occurrence of superoxiode anion in the reaction of reduced henazine methosulphate and molecular oxygen".Biochem. Biophys. Res. Commun., 46:844-853.

Pappas, N. J. (1989): Enhanced cardiac enzyme profile. Clin Lab Med, 9 (4):689-716.

Phyllis, E. (2012): Safety Evaluation and Hepatoprotective Activity of the Aqueous Stem Bark Extract of Spathodea campanulata Ph.D Thesis, KUMASI. 
Rivera, H.; Shibayama, M.; Tsutsumi, V.; Perez-Alvarez, V. and Muriel, P. (2008): Resveratrol and trimethylated resveratrol protect from acute liver damage induced by $\mathrm{CCl} 4$ in the rat. $\mathrm{J}$ Appl Toxicol; 28:147-155.

Roskams, T.; Baptista, A.; Bianchi, L.; Burt, A.; Callea, F.; Denk, H.; De Groote, J.; Desmet, V.; Hubscher, S.; Ishak, K.; MacSween, R.; Portmann, B.; Poulson, H.; Scheuer, P.; Terracciano, L. and Thaler, H. (2003): Histopathology of portal hypertension:a practical guideline. Histopathology; 42: 2-13.

Said, E.; Said, S. A.; Gameil, N. M. and Ammar, E. M. (2013): Modulation of thioacetamide-induced liver fibrosis/cirrhosis by sildenafil treatment. Can J Physiol Pharmacol. 91(12):1055-63.

Sanders, T. H.; Mc-Michael, R. W. and Hendrix, K. W. (2000): Occurrence of resveratrol in edible peanuts. J Agric Food Chem, 48: 1243-1246.

Sarkar, M. K. and Sil, P. C. (2007): Hepatocytes are protected by herb Phyllanthus niruri protein isolate against thioacetamide toxicity. Pathophysiology 14, 113-120.

Schmatz, R.; Perreira, L. B.; Stefanello, N.; Mazzanti, C.; Spanevello, R.; Gutierres, J.; Bagatini, M.; Martins, C. C.; Abdalla, F. H.; Daci da Silva Serres, J.; Zanini, D.; Vieira, J. M.; Cardoso, A. M.; Schetinger, M.R. and Morsch, V. M. (2012): Effects of resveratrol on biomarkers of oxidative stress and on the activity of delta amino levulinic acid dehydratase in liver and kidney of streptozotocin- induced diabetic rats. Biochimie; 94:374-383.

Sebai, H.; Sani, M.; Yacoubi, M. T, Aouani E.; Ghanem-Boughanmi N. and BenAttia M. (2010): Resveratrol, a red wine polyphenol, attenuates lipopolysaccharide-induced oxidative stress in rat liver. Ecotoxicology and Environmental Safety, 73: 1078-1083.

Sehirli, O.; Tozan, A.; Omurtag, G. Z.; Cetinel, S.; Contuk, G.; Gedik, N. and Sener, G. (2008): Protective effect of resveratrol against naphthaleneinduced oxidative stress in mice. Ecotoxicol. Environ. Saf. 71, 301308.

Sehrawat, A.; Khan, T. H.; Prasad, L. and Sultana, S. (2006): Butea monosperma and chemomodulation: Protective role against thioacetamide-mediated hepatic alterations in Wistar rats. Phytomedicine, 13: 157-163.

Seif El-Din, S. H.; Naglaa, M. El-Lakkany; Maha, B. Salem; Olfat A. Hammam; Samira, Saleh and Sanaa, S. Botros (2016): Resveratrol mitigates hepatic injury in rats by regulating oxidative stress, nuclear factor-kappa $\mathrm{B}$, and apoptosis. J Adv Pharm Technol Res; 7:99-104.

Shaker, M. E.; Salem, H. A.; Shiha, G. E. and Ibrahim, T. M. (2011a): Nilotinib counteracts thioacetamide-induced hepatic oxidative stress and attenuates liver fibrosis progression. Fundamental and Clinical Pharmacology, 25: 248-257.

Shaker, M. E.; Shiha, G. E. and Ibrahim, T. M. (2011b): Comparison of early treatment with low doses of nilotinib, imatinib and a clinically relevant dose of silymarin in thioacetamide-induced 
liver fibrosis. European Journal of Pharmacology, 670 (2-3) 593-600.

Simão, F.; Matté, A.; Matté, C.; Soares, F. M.; Wyse, A. T.; Netto, C. A. and Salbego C. G. (2011): Resveratrol prevents oxidative stress and inhibition of $\mathrm{Na}(+) \mathrm{K}(+)$-ATPase activity induced by transient global cerebral ischemia in rats. J. Nutr. Biochem, 22(10): 921-928.

SPSS (statistical package for social science) (2008): SPSS, 14.0 software.

Su, H. C.; Hung, L. M. and Chen, J. K. (2006): Resveratrol, a red wine antioxidant, possesses an insulin-like effect in streptozotocin-induced diabetic rats. Am. J Physiol Endocrinol Metab 290: E1339-E1346.

Suttorp, N.; Toepfer, W. and Roka, L. (1986): Antioxidant defense mechanisms of endothelial cells: glutathione redox cycle versus catalase, Am. J. Physiol. Cell Physiol. 251: C671-C680.

Tietz, N. W. (1995): Clinical Guide to Laboratory Tests 3rd ed., WB Saunders, Philadelphia, pp.306-309.

Tsai, M. K.; Lin, Y. L. and Huanga, Y. T. (2010): Effects of salvianolic acids on oxidative stress and hepatic fibrosis in rats. Toxicology and Applied Pharmacology, Volume 242, issue 2, Pages 155-164.
Vuyyuri, B.; Jyotsna, G. S. L. and Reshma, T. (2014): A Review on Hepatoprotective Activity .In.J Pharmaceut Sci Res. 5: 690-702.

Wang, J. H.; Shin, J. W.; Choi, M. K.; Kim, H. G. and Son, C. G. (2011c): An herbal fruit, Amomum xanthoides, ameliorates thioacetamide-induced hepatic fibrosis in rat via antioxidative system. Journal of Ethnopharmacology. 135(2): 344-350.

Wang, M. E..; Chen, Y. C.; Chen, I. S..; Hsieh, S. C.; Chen, S. S. and Chiu, C. H. (2012): Curcumin protects against thioacetamide- induced hepatic fibrosis by attenuating the inflammatory response and inducing apoptosis of damaged hepatocytes. $\mathbf{J}$ Nutr Biochem 23, 1352-66.

Zaleska, A.; Gorska, P.; Sobezak, J. W. and Hupka, J. (2007): Thioacetamid and thiourea impact on visible light activity of $\mathrm{TiO}_{2}$ Applied Catalalysis B: Environmental, 76: 1-8.

Zhang, F.; Ni, Y.; Yuan, Y.; Yin, W and Gao, Y. (2017): Early urinary candidate biomarker discovery in a rat thioacetamide induced-liver fibrosis model.doi: http://dx.doi.org/10.1101/125120. 